\title{
تحديد نسبة الكافيين في بعض مشروبات الطاقه
}

\section{ميمونه سعود الحربي1، فوزيـه معيض الحرب1، ريهام لفاء الحربي1، فايزة صنت الحربي1،

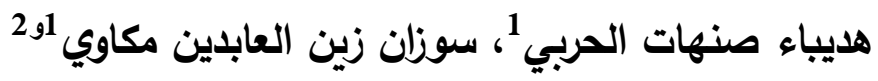

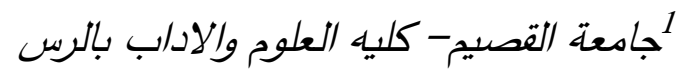 جامعة النيلين - كليه العلوم- الخرطوم- السودان النئ} Email:suzanmakawi@yahoo.com

الملفص: تم في هذه الدراسة جمع أربع عينات من شركات مختلفة من عدة أسواق محليه ، ومن ثم أجري عليها

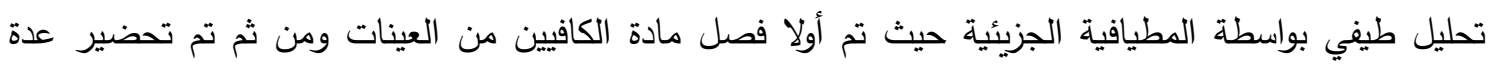

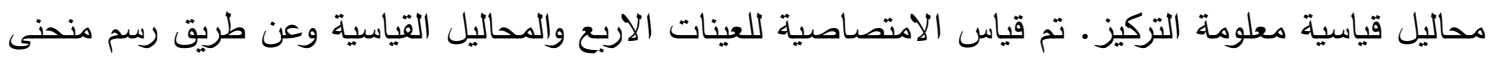

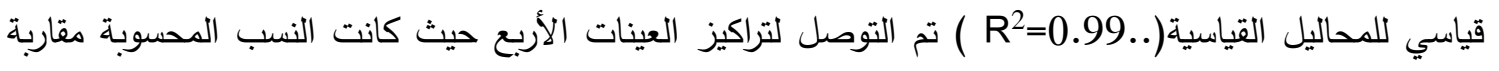

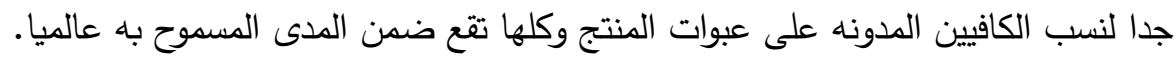
الكلمات المفتاحيه: كافيين، مشروبات الطاقه، المطيافيه الجزيئيه

المخدر على الجسم اذا زادت كمية استهلاكه عن

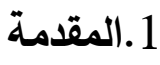

الكمية التي يتقبلها الجسم مما يؤدي إلى إدمانه كما : 1.1

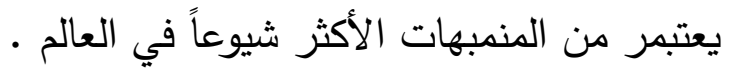
مادة شبه قلوية بلورية بيضاء اللون وعند تنقيتها

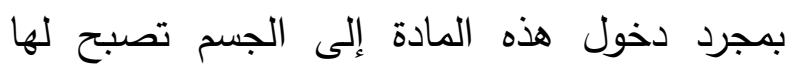

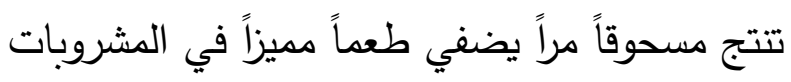

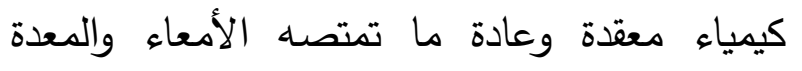
الغير محلاة ، ومحفزة للجهاز العصبي ولها تأثير 
خلال 45 دقيقةم ، وبعدها يتوزع في جميع أنسجة 2.1 تركيبه الكيميائي :

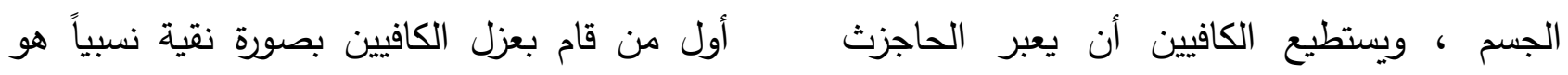

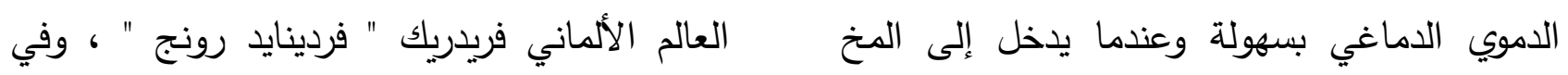

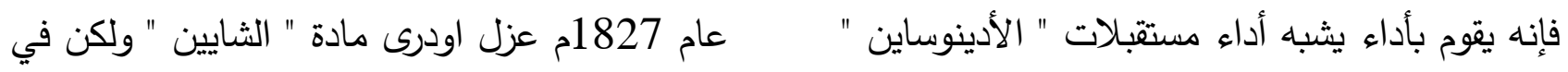

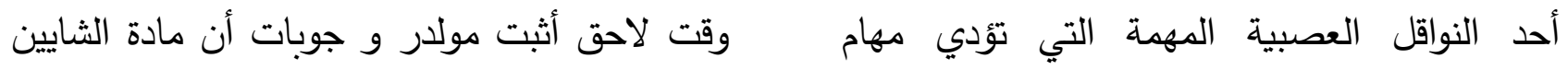

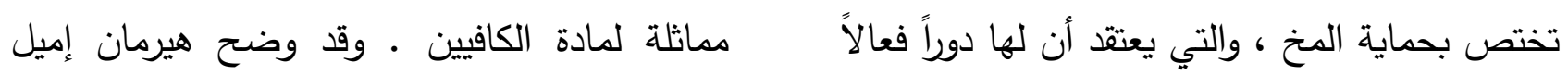

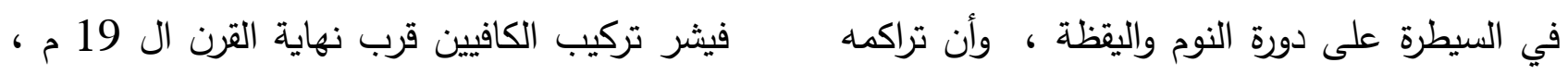

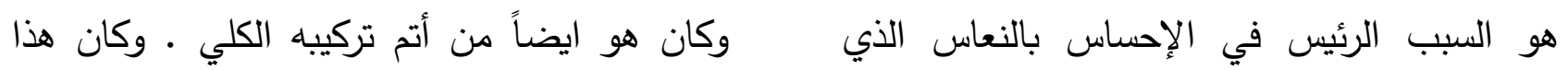

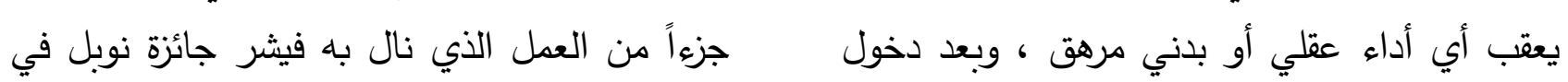

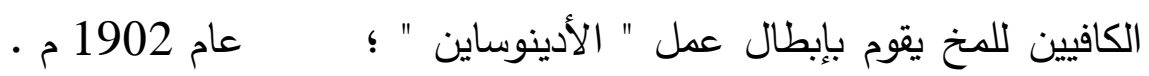
وربما لهذا السبب يساعد على اليقظة والانتباه يلى حيث أطلق على مادة الكافيين الاسم الكيمائي " وصفاء الذهن ، ويستمر تأثيره لمدة 4_6 ساعات الجزيئية "<smiles>Cn1c(=O)c2c(ncn2C)n(C)c1=O</smiles>

شكل(1.1) الصيغة البنائية للكافيين .

جميع ذرات الهيدروجين في الأساس مستويه " في تهجين مداري SP " مما أدى إلى إكساب جزيء الكافيين صفة عطرية . (2) 3.1 الخواص الكيميائية وإلفيزيائية للمادة الكافيين(2,3) : 
جدول(1.1) الخواص الفيزيائية والكيمائية للكافيين

\begin{tabular}{|c|c|}
\hline | & 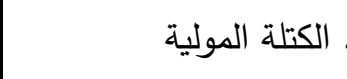 \\
\hline عديم الرائحة، على هيئة إبر بيضاء أو مسحوق . & مظهر خارجي \\
\hline | 1.2 غرام / متر 3. & 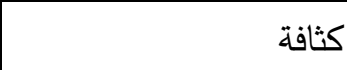 \\
\hline | قابل للذوبان قليلاً . & الذوبان في الماء \\
\hline 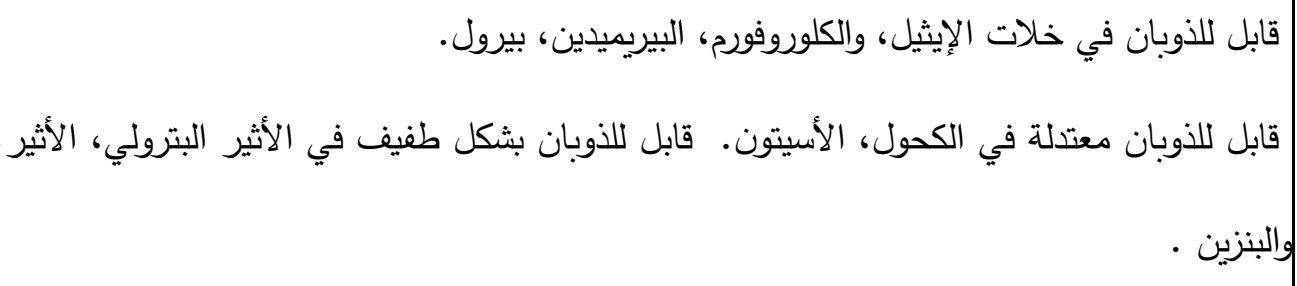 & الأخرى \\
\hline | 237 درجة مئوية . & نقطة الانصهار \\
\hline | 178 درجة مئوية . & نقطة الغليان \\
\hline
\end{tabular}

ب/ الثاي : ويحتوي على نسبة أقل من تلك

$$
\text { الموجودة في القهوة }
$$

أو تحضر صناعياً كالأنواع التي تصنع في المختبرات وتتت إضافتها إلى بعض العض الأدوية

$$
\text { ومشروبات الطاقة }
$$$$
\text { (4) والمياه الغازية }
$$

6.1

1.6.1 معدل الكافيين المسموح به :

يتقق الخبراء على أن الاستخدام المعتدل للكافيين لن

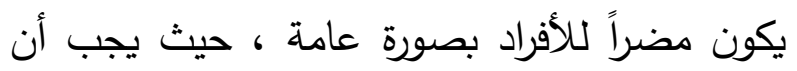

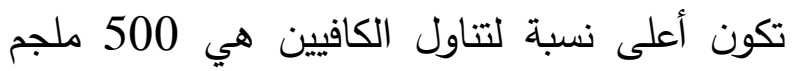
يومياً ، والنسبة المتوسطة 500.250 ملجم ، أما النسبة القليلة فهي أقل من 250 ملجم ، وقد تظهر
4.1 نشأته التاريخية :

قد بدأ استهلاك الكافيين منذ العصر الحجري ل وقتها كان السكان المحليون يعرفونه من خلال مضغ البذور والأوراق التي تبين لهم أن لها مفعولاً يثبه السحر في تخفيف حدة التعب وتحسين صفاء الذهن ، ويقال : إن إمبراطور الصين شيونج الذي تولى الحكم في عام 3000 قبل الميلاد هو الذي اكتثف بالصدفة انبعاث رائحة عطرية عند سقوط بعض أوراق الثاي في الماء المغلي وعندما تذوقها

زاد نشاطه . (3) 5.1 مصادر الكافيين : قد يتم استخلاصه طبيعياً من عدة مصادر مثل : أر القهوة : وتحتوي على كمية كبيرة جداً منه . 
من الكافيين يتراوح مقدارها ما بين 50.25 ملجرام كافٍ لغالبية الناس لأن يشعروا بالراحة وصفاء

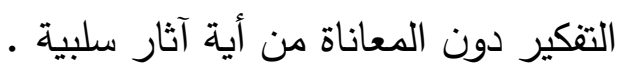

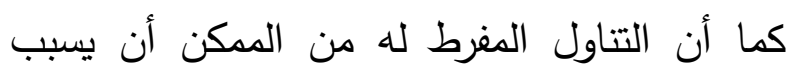
للشخص العصبية وارتجاف العضلات وقرحة المعدة والتسمم الكافييني ( تتاول جرعة تزيد عن 300 ملج من الكافيين يؤدي إلى تنشيط مفرط للجهاز

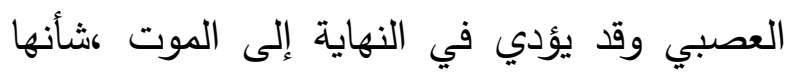
شأن أي تتاول الجرعات المفرطة لأي منشطات اخرى ). وتصل قيمة الاستهلاك العالمي له 120 ألف طن سنوياً لذا يعد من أكثر المشروبات تأثيراً في العالم

2.6.1 الأدوية والأعشاب الطبية التي تتعارض مع الكافيين :

بعض المضادات الحيوية مثل ادوية

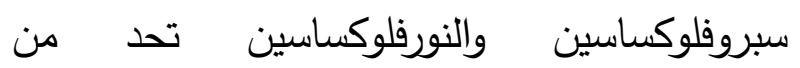
امتصاص الجسم للكافيين ولذلك تسبب ارتفاع نسبة مادة الكافيين في الدم وبالتالي تزيد من آثاره

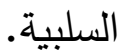
بالإضافة إلى أن بعض الأدوية التي تستخدم لتوسيع الثعب الهوائية مثل الأدوية التي تحتوي الإنى على مادة ثيوفيلين تسبب تأثير مشابه لمادة الكافيين

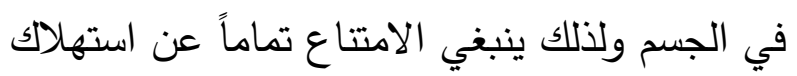
الكافيين عند تناول هذه الأدوية لتجنب زيادة تركيز هذه المواد في الدم مما قد يسبب بعض الآثار
الأعراض السلبية المذكورة آنفاً حتى مع تناول كمية

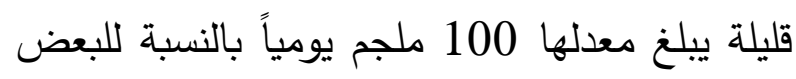
• فلكل منا نسب استجابة مختلفة للمواد التي يتم تناولها .

اوضحت الهيئة الاوروبية لسلامة الأغذية ان الحد المسموح به في اليوم لكل (EFSA) مصادر الكافيين هو 400 ملجم والجرعة الواحدة لا تتجاوز 200 ملجم. كما يقول د/واين سكوت اندرسون . الخبير الطبي Take Shape for Health ورئيس مؤسسة ومؤلف كتاب العادات الصحية " لا يتأثر الأشخاص بتتاول الكافيين إذا كانت بكميات معتدلة

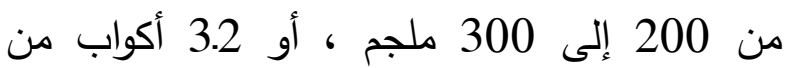
القهوة في اليوم ولكن يجب تتاولها خلال ساعات الصباح حتى ينحسر أثرها داخل الجسم بقدوم وقت لته النوم " الن كما أوضحت دراسة د/ كريستيان نورثرب ، خبير

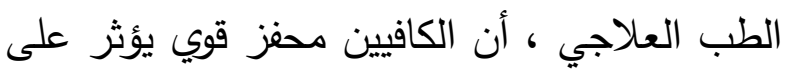
الجهاز العصبي المركزي وينعكس على حالتنا المزاجية في الحقيقة هو عقار يؤثر بشكل سلبي

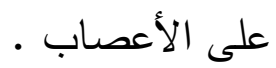
لهذا يجب على الفرد أن يضع نصب عينيه ان

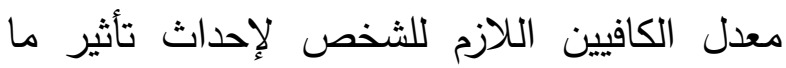
يختلف من شخص لآخر وفقاً لحجم الثخص ودرجة تحمله الفطرية للكافيين وهو يحتاج أقل من ساعة لتظهر نتائجه ، ولكن في الغالب تناول جرعة 
7.1 فوائد الكافيين واضراره: 1.7 .1 فوائده : ذكر تقرير علمي من الجامعة الوطنية في سينغافورة أن شرب فنجان من القهوة مفيد للمخ حيث يبطئ من تدهور الخلايا ويحافظ على حدة العقل وأضافت هذه الدراسة التي استمرت أربعة أعوام من قبل علماء في سينغافورة أن فائدة الكافيين للمخ تتشكل في أنه يحمي خلايا المخ من تراكم البروتين المدمر على مدار السنين ، ولكن يجب الأخذ بالاعتبار أن تناول الكميات الزائدة من الكافيين تصاحبها بعض الأعراض الجانبية كما ذكرناها سابقاً. كما تبين فائدته على المدى الطويل والقصير في علاج اضطرابات التنفس في الاختناق عند الولادة المبكرة والنمو الرئوي الثاذ لدى الأطفال؛ والمخاطرة الوحيدة قصيرة المدى والمقترنة بالعلاج هي الانخفاض المؤقت في الوزن أثناء فترة العلاج. كما أن تناول المشروبات التي تحتوي على الكافيين تساعد على الشعور بالانتباه واليقظة لفترة من الزمن حيث يزداد نشاط وتركيز العديد من الناس بعد تناوله كما أن العديد من الأدوية تحتوي على الكافيين مثل الأدوية المعالجة لحالات الإرهاق والنعاس ، ولقد أثبتت الدراسات العلمية الحديثة أن الن للكافيين القدرة على تقوية جهاز المناعة في الجسم والوقاية من مرض السرطان ومرض الخرف . وهناك دراسة أخيرة تقول بأن تناول الكافيين يمكن أن يقلل من خطورة تطور مرض الثلل ، وكما أن
الجانبية مثل : الشعور بالقيء أو زيادة خفقان القلب. وأيضاً نبتة القنفذية والتي تستخدم في الوقاية من نزلات البرد تسبب زيادة في تركيز الكافيين في الدم

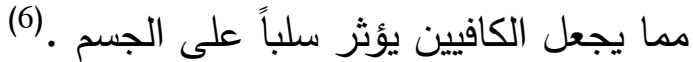
3.6.1 أعراض تناول الكافيين الجانبية : سرعة وعدم انتظام ضربات القلب ، العصبية ، حدة الطبع، الأرق، الارتعاش، الصداع، آلام البطن

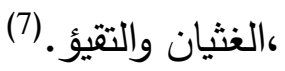
4.6.1 اعراض ارتفاع نسبة الكافيين: 1/العصبية الزائدة والهيجان والصداع وصعوبـة

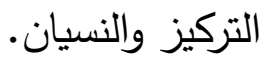
2/زيادة في معدل ضربات القلب والثعور بالخفقان. 3/القلق والأرق والاكتئاب والإرهاق والرعشة. كالاضطراب العام واضطراب المعدة . 5/ارتفاع ضغط الدم - الد

6)/ارتفاع مستوى الكوليسترول . (8) 5.6.1 اعراض فقدان الكافيين عند المتناولين له بكميات كبيره : 1/الصداع بأنواعه. 2/الرشح الأنفي. 3/الغثيان والقيء والإمساك. 4/ ازدياد الشهية والرغبة في الأكل. 5/الشعور بالبرودة والحرارة.

6/العصبية والاضطراب والدوخة وطنين الأذن . (9) 
كما يزيد من معدل التمثيل الغذائي الذي يساعد

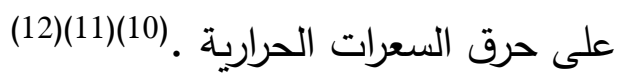
: 2.7.1 يرفع ضغط الدم ، و يزيد دقات القلب ، ويرفع نسبة السكر و الدهانات في الدم ، ويزيد من إفرازات

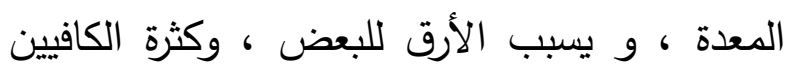

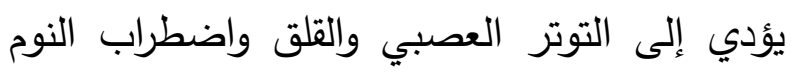

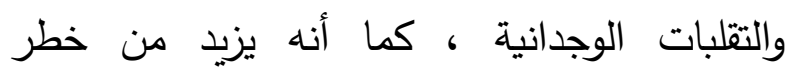
الإصابة ببعض الأمراض مثل : هثاشة العظام وأمراض القلب والسرطان . 1.2.7.1 الكافيين والأجنة :

يؤثر تتاول الكافيين على الجنين بشكل سلبي نظراً

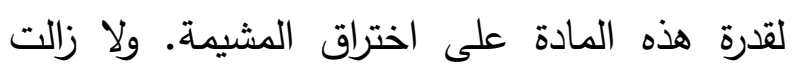
الأبحاث العلمية مستمرة لإيجاد الأثر الدقيق الذي الذئي

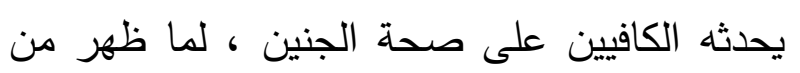
نتائج تثير إلى وجود صلة بين تناول الكافيين

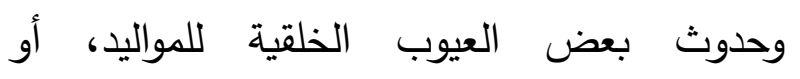

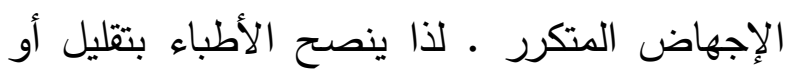

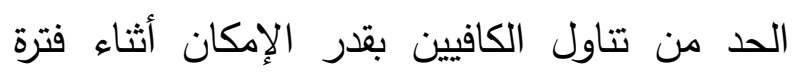
(13) الحمل 2.2.7.1 الكافيين والأطفال : تثير الدراسات إلى أن تناول الكافيين حتى 300

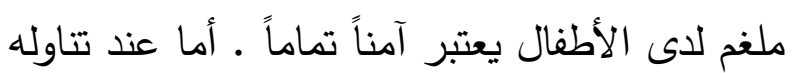
بكميات كبيرة فقد يؤدي الكافيين إلى تفاقم العصبية والخوف وخاصة بين الأطفال الذين لديهم حساسية

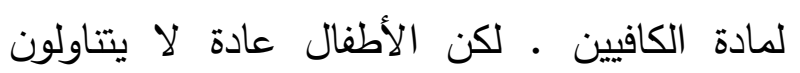

هناك دلالات تفيد أنه يقلل من تليف الكبد ، ويمكنه زيادة راحة معدل امتصاص الغذاء بالنسبة للنحيلين

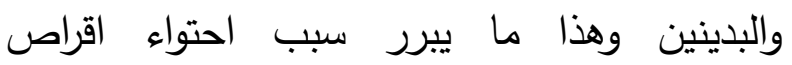
ومنتجات التخسيس بما فيها أقراص الحمية العشبية على مادة الكافيين. أما الأمر الجيد بخصوص تلك المادة هو أنهان أنها تزيد من معدل التمثيل الغذائي الذي يساعد على حرق الذي

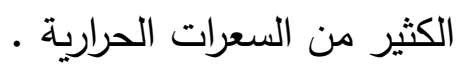
وفي تحليل لعدة دراسات وجد هيغنز أن 5 من أصل تسع دراسات تتاولت القهوة بشكلها العادي وكانت إيجابية هذا الموضوع زيادة التحمل والأداء البدني ؛ فاستهلاك الرياضيين لما يقارب 3 إلى 7 ملغم من الكافيين عن طريق القهوة يساهم في

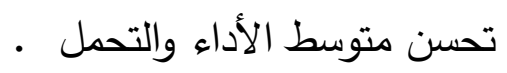
ولكن كان للدكتور كونلي " أستاذ التربية الرياضية بجامعة برمنجهام ينج في ولاية يوتا الأمريكية "

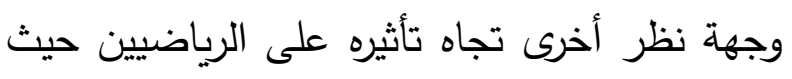

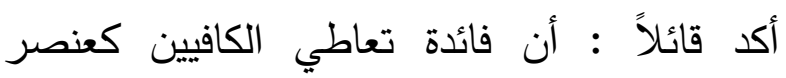
مساعد لرفع مستوى الأداء الرياضي سيؤدي وبشكل

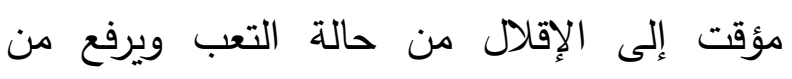
مستوى التركيز والانتباه ، وعلى ذلك فهو ينصح

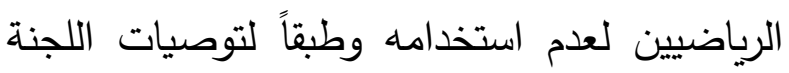

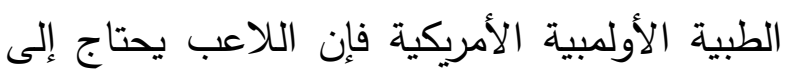

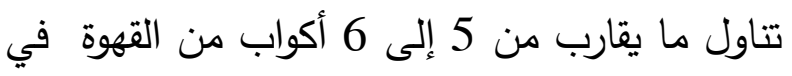
خلال ساعتين قبل بدء المسابقة في تمكين اتخاذ قرار بإيقافه أو استبعاده من المسابقة . 
4.2.7.1 الكافيين وضغط الدم :

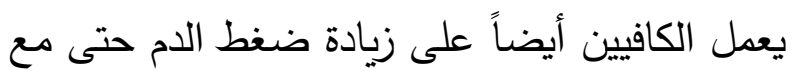
الأفراد الأصحاء لكنه يزيد بصورة أكبر مع كبار

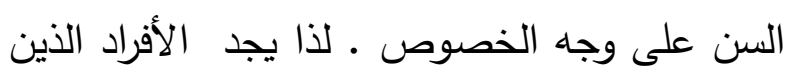

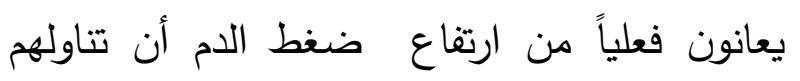
كميات كبيرة من الكافيين يزيد من نسبة ارتفاع

ضغط الدم لديهم إلى مستويات غير مرغوبة .

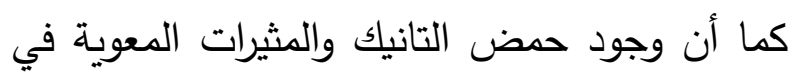
كثير من المشروبات التي تحتوي على الكافيين يؤدي إلى إعاقة الامتصاص المناسب للموبات لهوبي الغذائية والمعادن التي يحتاجها الجسم من أجل أداء

وظائفه بصورة ملائمة . 5.2.7.1 الكافيين والسكر والكولسترول : أكدت دراسة نشرت عام 2004م أن المصابين بالسكري يعانون من ارتفاع في مستوى السكر في الدم إثر تتاولهم القهوة بشكل منتظم. كما أن هناك دلائل تثير إلى أن الإفراط الثديد في

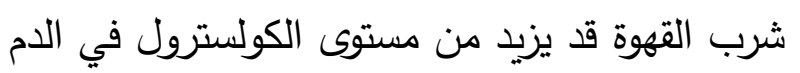

6.2.7.1 الكافيين والذاكرة المؤقتة : نشرت إذاعة بي بي سي على موقعها في عام

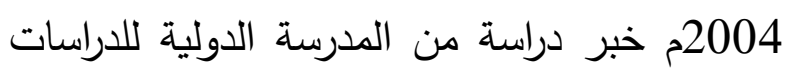
المتقدمة في إيطاليا يقول: بأن الكافيين يمكن أن يعيق الذاكرة المؤقتة. "من يحتاج إلى الكافيين وهل هنالك أضرار من
القهوة ، بل غيرها من المشروبات التي تحتوي على

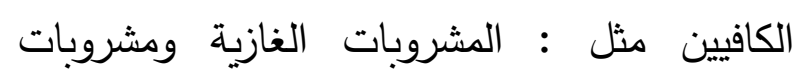
الطاقة أو الثاي بأنواعه المختلفة ـ هذه المشروبات المثنات تحتوي على مستويات مرتفعة من السكر وكمية من

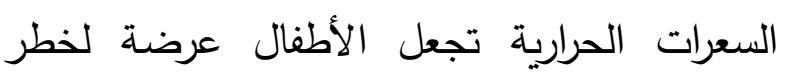
(14). السمنة كما أن الكافيين يعمل بصورة سيئة في استنفاذ كافة الفيتامينات والمعادن من الجسم وبصفة خاصنة الكالسيوم والكالسيوم من أهم المواد الضرورية لبناء عظام قوية لدى الأطفال . 3.2.7.1 الكافيين والمرأة :

يتم امتصاص مادة الكافيين بثكل أبطأ عند المرأة

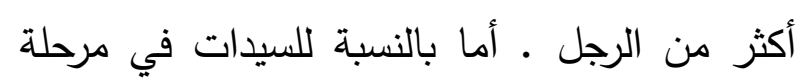

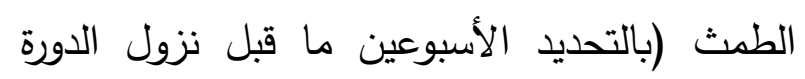
الثهرية ) أو ممن يتتاولن حبوب منع الحمل تأخذ الأند عملية الامتصاص وقت أطول يصل إلى ساعتين لكي يستطيع الكبد امتصاص المادة ؛ فتتاول عبوة الكي سئل

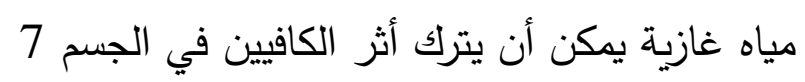

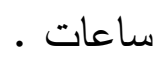
كما أن الكافيين يمكن أن يساعد على تضخم حجم

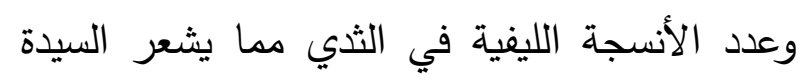
ببعض التكتلات والآلام ومع وجود هذه التكتلات

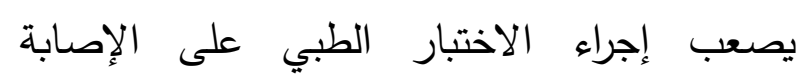
بسرطان الثدي ودائماً ما ينصح بتجنب الكافيين لدى السيدات التي سبق إصابتهن بسرطان الثدي 
تعتبر من الأسئلة المثيرة للاهتمام ، فلا أحد حقاً 8.18 نسبة الكافيين في بعض المشروبات

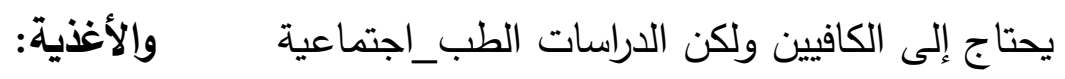

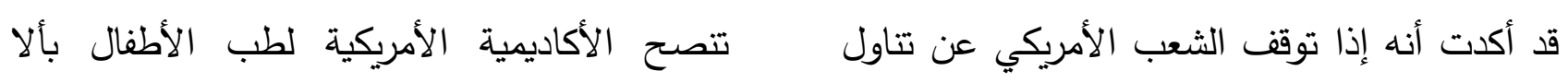
القهوة أو الثاي أو المشروبات التي تحتوي على يستهلك المراهقون أكثر من 100 مليجرام من

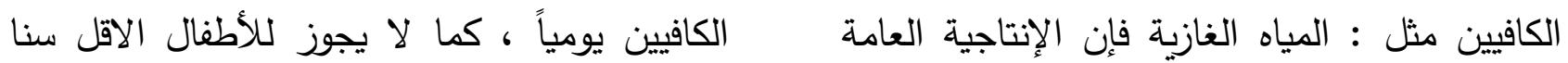
استهلاك المشوبات التي تحتوي على لألى الكافيين كقاعدة ثابتة. 120 ألف طن سنوياً قيمة الاستهلاك العالمي للكافيين، ومن خلال الجداول التاليه نستعرض كمية الكافيين في بعض المشروبات

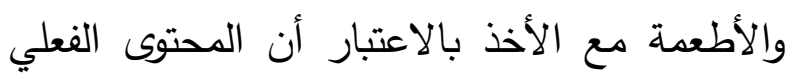
للكافيين لنفس مشروب القهوة أو الثاي قد يتغير الإني

من يوم ليوم •(19)

القهوة : سوف تتخفض بنسبة 60\% ـ لذلك يمكن لمن يريد المزيد من اليقظة والقدرة على التحمل استخدام كمية كافية وقليلة من الكافيين يومياً . كذلك يمكن لمن يريد أن يتجنب الآثار الضارة

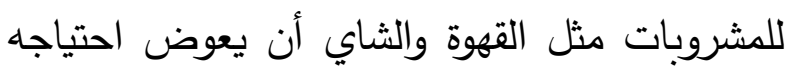
للكافيين بالحصول عليه في صورة مكملات والتي تحتوي على مستخلص الكافيين النقي ولكن نؤكد أن نقص الكافيين أو عدم تزويد الجسم به لا ينتج عنه أية مشاكل وكذلك فإن الكافيين ليس من مصادر

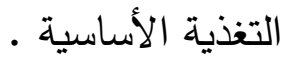

جدول(2.1) نسبة الكافيين في القهوة .

\begin{tabular}{|c|c|c|}
\hline ل نوع القهوة & 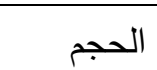 & الكفايين \\
\hline اسبرسو، الحجم الكلاسيكي & م 30 & 75-40ملغرام \\
\hline اسبرسو، الحجم الكلاسيكي، منزوع الكفايين & 30 & 15-0ملغرام \\
\hline |القهوة العربية (فنجان) & 30 3لمل & 40 4ملغرام \\
\hline مخمر عام (مغلية) & 240ملل & 200-95ملغرام \\
\hline مخمر عام، منزوع الكفايين (مغلية) & 240ملل & 12-2ملغرام \\
\hline سهل الذوبان، عام & 240ملل & 173-27ملغرام \\
\hline سهل الذوبان، عام، منزوع الكفايين & 240ملل & 12-2ملغرام \\
\hline ماكدونالدز متخمر (مغلية) & 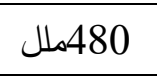 & 1001ملغرام \\
\hline ماكدونالدز موكا فراب & 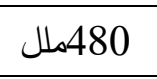 & 125 ملغرام \\
\hline قهوة بالحليب ستارباكس (لاتيه) & 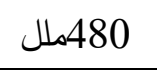 & 1501ملغرام \\
\hline
\end{tabular}


جدول(3.1) نسبة الكافيين في الثاي .

\begin{tabular}{|c|c|c|}
\hline نوع الثاي & 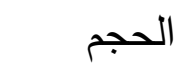 & الكفايين \\
\hline شاي اسود & 240ملل & 14-61-6لغرام \\
\hline شاي اخضر & 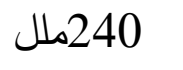 & 40-24-20لغرام \\
\hline شاي متلج اريزونا، بنكهة الليمون & 240ملل & 11 ملغرام \\
\hline سريع الذوبان، عام، غير محلى & 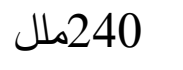 & 26ملغرام \\
\hline ليبتون قوي النكهة مثلج بالليمون & 240ملل & 5-7ملغرام \\
\hline
\end{tabular}

مشروبات غازبه :

جدول(4.1) نسبة الكافيين في المياه الغازية .

\begin{tabular}{|c|c|c|}
\hline نوع المشروب & الحجم & الكفايين \\
\hline سفن اب & 355ملل & 0 ملغرام \\
\hline بيرة جذور & 355ملل & 0 ملغرام \\
\hline Barq's بيرة جذور & 355ملل & 18 ملغرام \\
\hline كوكا كولا كلاسيك & 355ملل & 35-30ملغرام \\
\hline كوكا كولا زيرو & 355ملل & 35ملغرام \\
\hline دايت كولا & 355ملل & 47-38ملغرام \\
\hline دايت بييسي & 355ملل & 37-27ملغرام \\
\hline ماونتين ديو & 355ملل & 36ملغرام \\
\hline بيبسي & 355ملل & 55-46ملغرام \\
\hline سبرايت & 355ملل & 39-32ملغرام \\
\hline
\end{tabular}


مشروبات الطاقة:

جدول(5.1) نسبة الكافيين في مشروبات الطاقة

\begin{tabular}{|c|c|c|}
\hline المشروب & الحجم & الكافيين \\
\hline بايسن & 100 مل & 32 ملفم \\
\hline بغزي & 100مل & 30 ملغم \\
\hline كودرد & 100 مل & 30 ملفم \\
\hline تورين & 100 مل & 30 ملفم \\
\hline
\end{tabular}

الصحية المرتبطة بها، وبالتالي القلق العالمي من هذا الموضوع، وأوضحوا أن مبيعات مشروبات

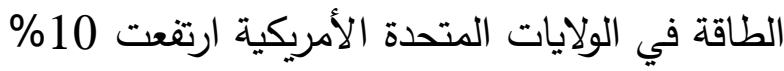
سنوياً ما بين عامي 2008 و 2012، كما أن الن 500 علامة تجارية جديدة مختصة في تصنيع مشروبات الطاقة ظهرت في الأسواق في عام .2006

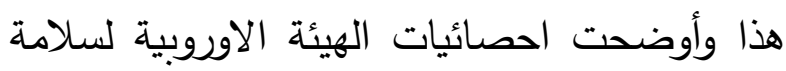
الأغذية أن 30\% من البالغيت يتناولون مشروبات

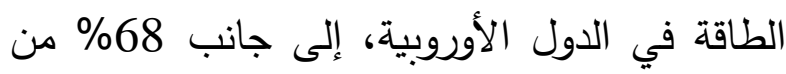
المراهقين، و18\% ممن هم دون العاشرة من عمرهم أيضاً. وتكمن مخاطر استهلالك مشروبات الطاقة باحتوائها على مستويات عالية من الكافيين، فعلى العكس من المشروبات الساخنة الأخرى التي تحتوي على الكافيين، بالإمكان تناول مشروبات الطاقة جرعة واحدة مما يزيد من خطر الإصابة بتسمم الكافيين caffeine intoxication
9.1 مخاطر مشروبات الطاقة: حذر فريق من منظمة الصحة العالمية WHO في Frontiers in Public بيان نشر على موقع من منئ من الاستهلاك المتزايد لمشروبات الطاقة Health

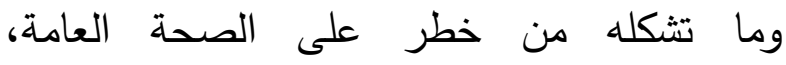
وبالأخص بين صفوف الثباب. مشروبات الطاقة عبارة عن مشروبات غير كحولية، وتحتوي على لئ الكافيين والفيتامينات ومواد أخرى مثل تورين taurine (guarana) وتزيد من الأداء البدني والعقلي. ومن اجل ذلك قام

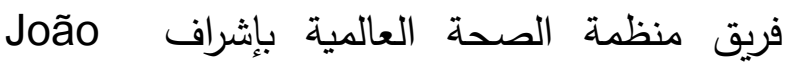
Breda استهلاك هذه المشروبات بالإضافة إلى العواقب لاقب والسياسات المتعلقة بتتاولها. وأثار الباحثون والخبراء بأنه نظراً لزيادة الإقبال

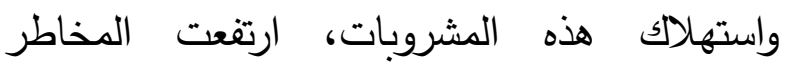




\section{تحضير المحلول القياسي :}

حضر محلول قياسي 100ppm وذلك

بإذابة $0.01 \mathrm{من} \mathrm{الكافيين} \mathrm{النقي} \mathrm{في} \mathrm{100ml} \mathrm{من}$

الكلوروفورم في دورق حجمي سعته 100ml ـ إدابه

تحضير المحاليل القياسية ذات تراكيز مختلفة :

في دوارق حجميه سعتها 100ml وضع فيها 10ml -20ml-30ml-40ml ) الأحجام التالية ) من المحلول القياسي السابق تحضيره وأضيف (لامليف

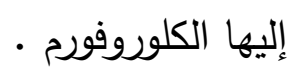
تحضير العينات : تم التخلص من غاز ثاني اوكسيد الكربون في العينات أخذ 5ml من كل العينة ووضعت في قمع الفصل. و أضيف إليها 10ml من الماء المقطر و ثم أضيف إليها $1 \mathrm{ml}$ من كربونات الصوديوم 20\% (وذلك بإذابة 10g من كربونات الصوديوم في 50 ml من الماء المقطر) . ثم أضيف 20ml من الكلوروفورم ـ أغلق قمع من الماء الفصل و رج الخليط جيداً لمدة خمس دقائق . ترك قمع الفصل يستقر لكي تنفصل الطبقة العضوية عن الطبقة المائية ثم فتح صمام القدع وجمعت الطبقة العضوية في دورق حجمي .

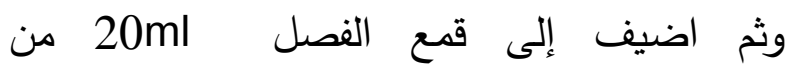
الكلوروفورم ثم يفصل و يكرر ذلك ثلاث مرات لكل عينة .

تم التخلص بعد ذلك من الطبقة المائية ، أما

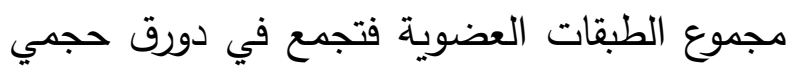

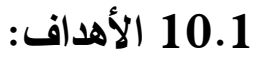
1/ استخلاص مادة الكافيين من عينات مختلفة من

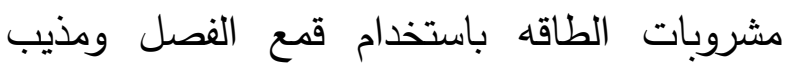

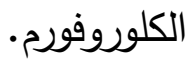

2 تقدير نسبة الكافيين في هذه المشروبات باستخدام جهاز المطيافية الجزيئية . 3/ مقارنة نسب الكافيين في العينات بالنسب لهبل المجدوله علي علب المنتج وبالحدود المسموح بها

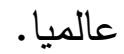

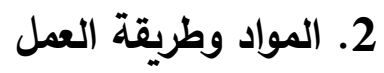
: 1.2 تم جمع أربع عينات من مشروبات الطاقة الموجودة في الأسواق المحلية واعطيت الرموز ( K,X,Z,B ) 2.2 الأدوات والكيماويات : SPECTRO UV-VIS RS

SPECTROPHOTOMETER UV-2502 LaboMed,inc - U.S.A • • (50mL - 100mL ) (دوارق حجميه سعة ( • قمع فصل

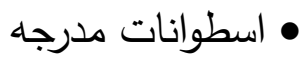

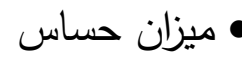

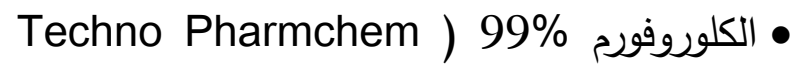
( Haryana _ India • كربونات الصوديوم 20\% • (ماء مقطر

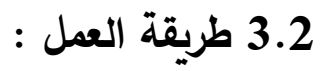


فإذا كان مجموع الطبقة العضوية أقل من 50ml أضف إليها كلوروفورم حتى 50ml بينما إذا كانت من امتصاصيات المحاليل القياسية معلومة التراكيز

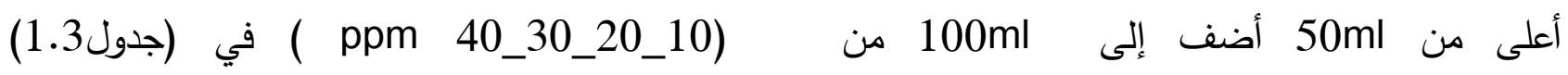
وباستخدام المنحنى القياسي للكافيين (شكل (1.3)

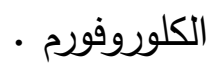

ت $\quad(Y=0.0017 x-0.0001) \quad\left(R^{2}=0,9977\right)$ قياس الامتصاصيات: تحديد تراكيز الكافيين في العينات المختلفة كما في (3.3) (جدول)

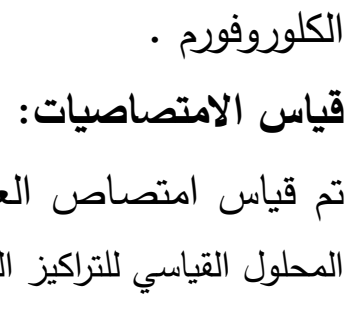
بواسطة جهاز المطيافية الجزيئية عند طول موجي . 270nm

جدول (1.3) امتصاصيات المحاليل القياسية للكافيين .

\begin{tabular}{|r|r|}
\hline التركيز & $(\mathrm{i})$ \\
\hline 0.016 & 10 \\
\hline 0.034 & 20 \\
\hline 0.055 & 30 \\
\hline 0.064 & 40 \\
\hline 0.170 & 100 \\
\hline
\end{tabular}

جدول (2.3) امتصاصيات العينات .

\begin{tabular}{|r|r|}
\hline رمز العينة & $\mathrm{B}$ \\
\hline 0.590 & $\mathrm{Z}$ \\
\hline 0.730 & $\mathrm{Z}$ \\
\hline 0.516 & $\mathrm{~K}$ \\
\hline 0.440 & $\mathrm{~K}$ \\
\hline
\end{tabular}

جدول (3.3) تراكيز العينات(ppm) .

\begin{tabular}{|r|r|}
\hline رمز العينة & $\mathrm{B}$ \\
\hline $347 \mathrm{ppm}$ & $\mathrm{B}$ \\
\hline $429.3529 \mathrm{ppm}$ & $\mathrm{X}$ \\
\hline $303.4705 \mathrm{ppm}$ & $\mathrm{K}$ \\
\hline $429.3529 \mathrm{ppm}$ & (لتركز \\
\hline
\end{tabular}


جدول (4.3)تركيز العينات ب( (mg/100ml)

\begin{tabular}{|r|r|}
\hline رمز العينة & B \\
\hline $34.7 \mathrm{mg} / \mathrm{ml}$ & $\mathrm{Z}$ \\
\hline $40.93 \mathrm{mg} / \mathrm{ml}$ & $\mathrm{X}$ \\
\hline $30.34 \mathrm{mg} / \mathrm{ml}$ & $\mathrm{K}$ \\
\hline $42.93 \mathrm{mg} / \mathrm{ml}$ & \\
\hline
\end{tabular}

من الجدول (4.3) وجد أن قيم تراكيز الكافيين في العينات كانت مقاربة للقيم المحددة على المنتج (تقريبا

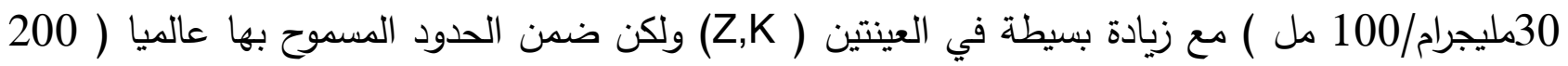

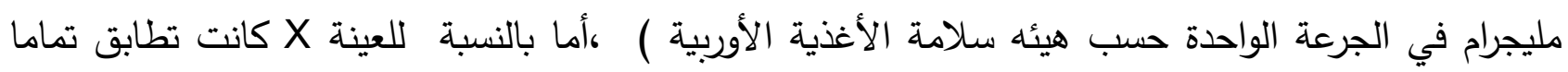

التركيز الموجود على المنتج ( 30.3 مليجرام/مل)

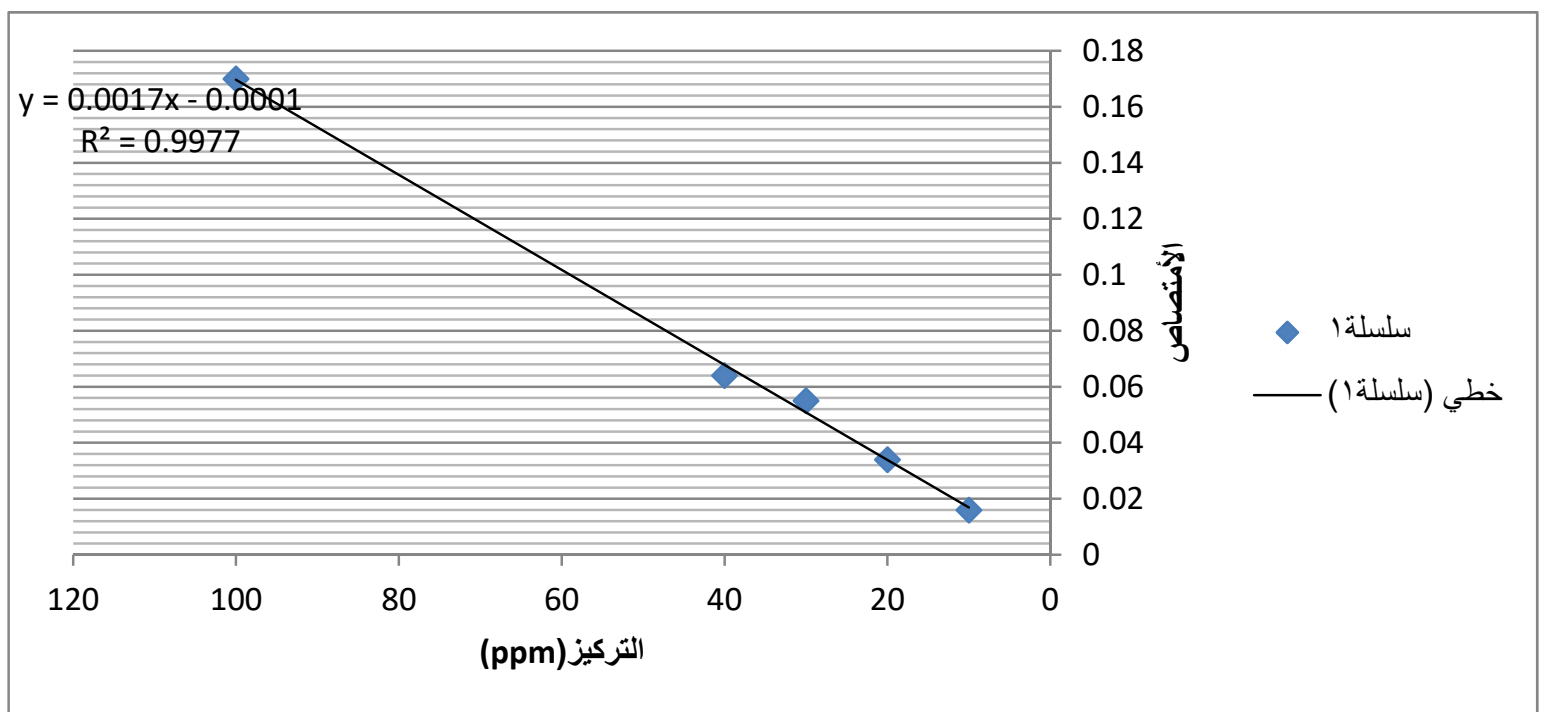

الثكل (1.3) المنحنى القياسي للكافيين

سلامة الأغذية الأوروبية) لذا ينصح بان لا يتجاوز عدد

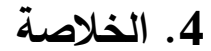

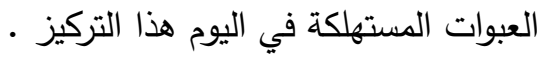

- عند تناول الكافيين بكميات عالية سيؤدي ذلك لأضرار عدة الكات

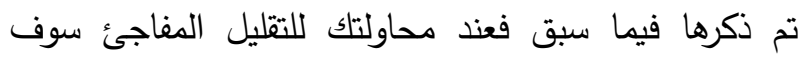
تظهر عليك اعراض نتص الكافيين التي سبق وان ذكرناها؛
0.18

0.16

0.1

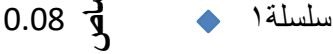

0.06

0.04

0.02

\section{政}


6- صابرين حسان محمد(2013). الأدوية والأعثاب الطبية التي تتعارض مع الكافيين ،مجلة حياتك،،عنوان الموقع http://hayatouki.com 7- د/ عبير مبارك (2008). أعراض تناول الكافيين

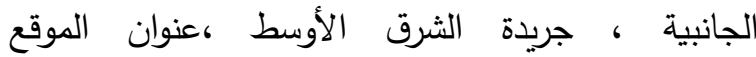
http://archive.aawsat.com 8- مؤسسة تقنية المعلومات(c016) .علامات ارتفاع نسبة health.com-الكافيين ،صحة البيوت، عنوان الموقع البعان www.allabouthttp://

-9 - أسماء النهراوي(2010) علامات انخفاض نسبة

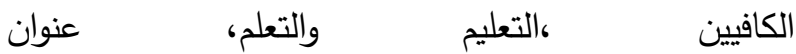

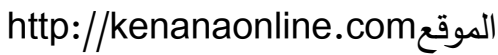
10- صابرين حسان محمد(2013). فوائد الكافيين ،مجلة حttp://hayatouki.com حياتك،،عنوان الموقعاين 11- إيمان إدريس محمد (2013). فوائد الكافيين، مجلة

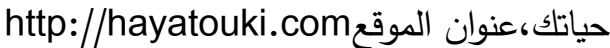
12- محمد (2011). فوائد الكافيين، عنوان الموقع http://forum.kooora.com

13- سلوي فتحي(2013) ـ الكافيين والأجنة ، الأهرام

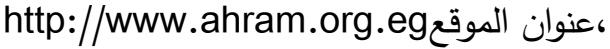
14- موقع صحة (2012). الكافيين والأطفال، عنوان http://www.sehha.com الموقع المانع 15- د/ وندى مانثستر ابراهيم (2013). الكافيين والمرأة،

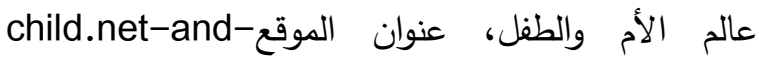
http://mother

16- د/ عبير مبارك (2008). الكافيين وضغط الدم ،جريدة

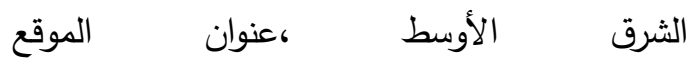

http://archive.aawsat.com

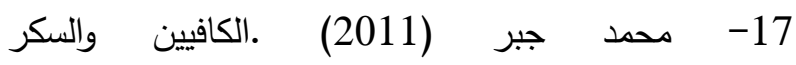
http://forum.kooora.com والكوليسترول،عنوان الموقع
لذا يفضل التقليل من كمية المشروبات المحتوية على الكافيين بالتدريج فمثلا : -النشاط والرياضة المستمرة خير منبه ومنشط للجسم. - غلي الثاي لمدة طويلة قد يزيد من نسبة الكافيين لذا من الافضل عدم تركه يغلي فترة طويله كما يفضل استخدام

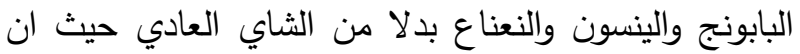
هذه المشروبات لا تحتوي على الكافيين .(20) (21) (22)

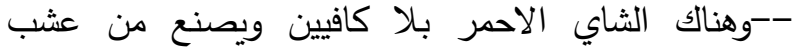
الرويبوس وهو غني بالمواد المضادة للأكسدة، ويمكن لعشب الرويبوس ان يساعد في علاج مشاكل صحية مثل الصداع والربو والمغص والارق ، كما يمكن ان يكون مفيدا لمن

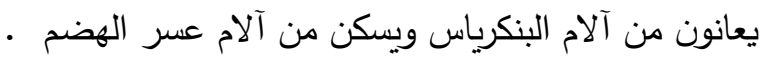

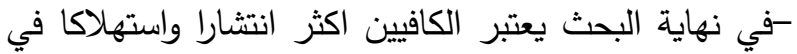
العالم وانه تم تحديد مصادرها والنسبة المسموح لثخص تناوله وكانت النتائج ان تأثيره يختلف من شخص لأخر وان تظهر اعراض عند الزيادة منه وكذلك عند التقليل منه للشخص المدمن عليه . - الماع. 5/ المراجع

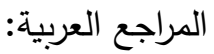
1- هاله رؤوف أحمد (2010) .الكافيين مجلة الألوكة ، chttp://www.alukah.net عنوان الموقع 2- إيمان إدريس محمد (2017). التركيب الكيميائي،شيء http://twitmail.comer الكافيين ،عنوان الموقع 3- هاله رؤوف أحمد (2010) .نثأته التاريخية مجلة http://www.alukah.net الألوكة، عنوان الموقله 4- صابرين حسان محمد(2013). مصادر الكافيين ،مجلة

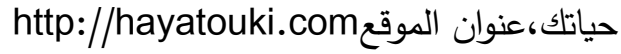
5- جريدة الثرق الأوسط(2008) معدل الكافيين المسموح

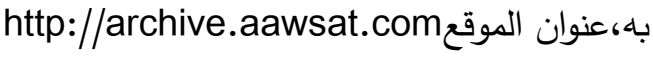




$$
\begin{aligned}
& \text { 18- محمد جبر(2014). الكافيين والسكر والكوليسترول، 21- د/ عبير مبارك (2008). الخلاصة والتوصيات، }
\end{aligned}
$$

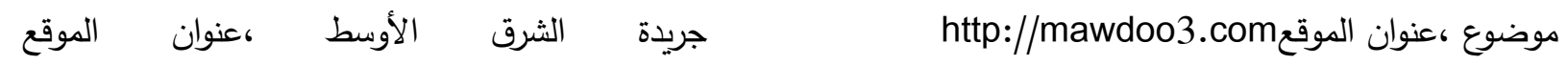

$$
\begin{aligned}
& \text { http://archive.aawsat.com مؤسيسة مايو للتعليم الطبي والبحوث(2011). نسبة }
\end{aligned}
$$

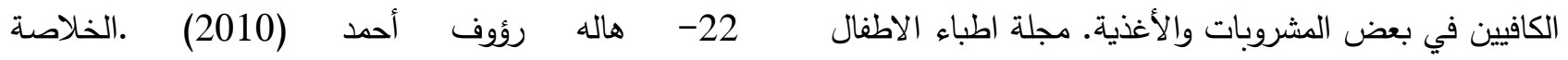

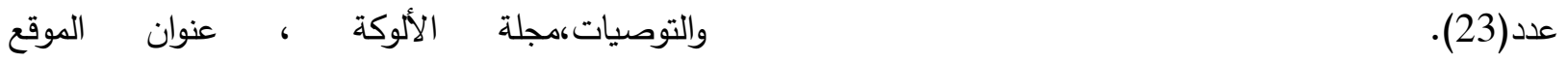

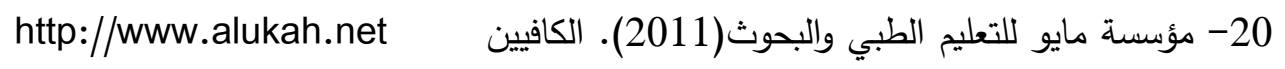

$$
\begin{aligned}
& \text { الخلاصة والتوصيات، مجلة اطباء الاطفال عدد(23). }
\end{aligned}
$$

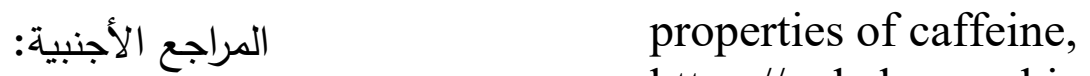

$$
\begin{aligned}
& \text { 23- Pubchem } \\
& \text { https://pubchem.ncbi.nlm.nih.gov }
\end{aligned}
$$




\title{
Determination of Caffeine Percentage in Some Energy Drinks
}

\author{
Maymounah Suad Alharbi ${ }^{1}$, Fayzayah Maedh Alharbi ${ }^{1}$, Reham Lefah Alharbi ${ }^{1}$, Fayzah Sanat \\ Alharbi ${ }^{1}$, Hadbah Sunhat Alharbi ${ }^{1}$ and Suzan Zain Alabdeen Makawi ${ }^{1,2}$ \\ ${ }^{1}$ Faculty of Science and Arts, Qassim University Alruss, Saudi Arabia \\ ${ }^{2}$ Faculty of Science, University of Alnileen, Khartoum, Sudan
}

\begin{abstract}
In this study 4 samples of energy drinks were collected from different local markets. The caffeine was separated and the standard solutions ware prepared then the absorption was recorded to all samples using UV-Vis spectrophotometer $\left(\mathrm{R}^{2}=0.9977\right)$. the results of al 1 caffeine samples ware compared to caffeine in bottle label and standard limits the results showed conformity of these labeling and standards
\end{abstract}

Keywords: caffeine, energy drinks, using UV-Vis spectrophotometer 